\title{
Preparation, characterization and electrocatalytic activity for oxygen reduction reaction in PEMFCs of bimetallic PdNi nanoalloy
}

\author{
E. F. Abo Zeid ${ }^{1}$ I. A. Ibrahem ${ }^{2}$
}

Received: 14 May 2017/ Accepted: 8 September 2017/Published online: 16 September 2017

(c) The Author(s) 2017. This article is an open access publication

\begin{abstract}
The modified polyol reduction method was used to prepare a carbon-supported bimetallic PdNi nanoalloys (BMNAs). The prepared catalyst was characterized using $\mathrm{X}$-ray diffraction and transmission electron microscopy. The obtained data indicated that, the average particle size of the alloys in the range $\approx 20-50 \mathrm{~nm}$. The morphology structure shows uniformly distributed particles on the supported carbon surface. The catalytic activity of the compounds for oxygen reduction reaction was investigated by cyclic voltammetry and electrochemical polarization measurements in rotating disk electrodes. As a function of time and calcination temperature, the improved activity and stability were obtained at $300{ }^{\circ} \mathrm{C}$ for $3 \mathrm{~h}$.
\end{abstract}

Keywords Nanoalloy PdNi/C · Electrocatalyst · Oxygen reduction reaction Proton exchange membrane fuel cell

\section{Introduction}

Modern researches dealing with technological development in the field of economics of hydrogen fuel cells have become furthermore paramount. Bimetallic nanoalloys (BMNAs) formed by incorporation of transition metal with noble metal are found to be effective in the field of catalysis due to their unique role of controlling the activity, selectivity and stability as catalysts [1-5]. As a

E. F. Abo Zeid

esabozaid@yahoo.com; eabozaid@aun.edu.eg

1 Physics Department, Faculty of Science, Assiut University, Assiut 71516, Egypt

2 Chemistry Department, Faculty of Science, Al-Azhar University, Cairo, Egypt consequence of the bimetallic union, the electronic-structural modifications drastically influence the catalytic performance of the mixed-metal catalyst systems showing enhancement in specific properties at an optimum composition because of the synergistic effect of the composition [6-9]. Among various non-platinum cathode catalysts, palladium has attracted considerable attention due to its promising application potential as cathode electrocatalysts in proton exchange membrane fuel cells (PEMFCs) [10-12]. The interest in Pd is not only for the purpose to lower the cost of catalysts but pursuits an improved catalytic activity [13-15]. The catalytic activity of Pd can be modified by alloying with metals having smaller atomic size such as $\mathrm{V}, \mathrm{Cr}, \mathrm{Fe}, \mathrm{Co}$ and $\mathrm{Ni}$ is particularly effective in enhancing the catalytic activity [16-22]. Due to the higher electronic density of nickel compared with the other metals in the first transition series, the metallic bond with palladium is stronger which results in increasing and improving the process of catalytic activity [23-31]. Ni is the most choice to alloy with Pd to enhance its activity and stability. In addition, the combination of $\mathrm{Pd}$ with $\mathrm{Ni}$ is expected to further enhance the tolerance of $\mathrm{Pd}$ to poisoning as $\mathrm{Ni}$ is an oxophilic element [32].

The oxygen reduction reaction (ORR) in a PEMFC cathode represents the prevalent challenge because of its sluggish kinetics limiting the overall PEMFC performance [33, 34]. Palladium nanoalloys are being currently used to accelerate the kinetics on the cathode electrode obtaining the maximum catalytic activity towards the ORR $[18,35]$. In the present work, a modified polyol reduction method used to synthesize a nanostructured carbon-supported PdNi catalyst to improve the electrochemical performance of $\mathrm{Pd}$ catalysts. The effect of heat treatment on the stability, activity and morphology structure of the bimetallic nanocatalyst are characterized by X-ray diffraction (XRD), 
transmission electron microscopy (TEM), cyclic voltammetry $(\mathrm{CV})$, and electrochemical polarization measurements in rotating disk electrodes.

\section{Materials and methods}

Metal salts $\left(\mathrm{NH}_{4}\right)_{2} \mathrm{PdCl}_{4}$ and $\mathrm{NiCl}_{2} \cdot 6 \mathrm{H}_{2} \mathrm{O}$ was provided from Daejung Chemicals and Metals Co., Ltd. (98.5\%). Ionic PDDA (35 wt\% in water, molecular weight about 10,000) and ethylene glycol (EG) from Samchun Pure Chemical Co., Ltd. (99.5\%). Sodium borohydride $\left(\mathrm{NaBH}_{4}\right)$ and carbon (Vulcan XC 72R) from Kanto Chemical Co., Inc. $(92 \%)$. All chemicals were analytic grade and used without further purification.

A modified polyol reduction method was used to synthesis of carbon-supported $\mathrm{Pd}_{68} \mathrm{Ni}_{32}$ bimetallic nanocatalyst. PdNi precursor solution was prepared as follows: required amounts of the metallic salts of Pd and $\mathrm{Ni}$ to obtain $100 \mathrm{mg}$ of bimetallic were dissolved in deionized water. About $30 \mathrm{~mL}$ of ionic PDDA was added to $30 \mathrm{~mL}$ of EG and sonicated for $15 \mathrm{~min}$. A volume of $40 \mathrm{~mL}$ of EG refluxed at $130{ }^{\circ} \mathrm{C}$ under stirring. PDDA and PdNi solutions were added dropwise to the EG under stirring for ten times with the appropriate amounts to give an atomic ratio of PDDA: $\mathrm{Pd}_{68} \mathrm{Ni}_{32}=7: 1$, after vigorous stirring for $1 \mathrm{~h}$, a reduction process of $\mathrm{Pd}$ and $\mathrm{Ni}$ ions occurred by adding a fresh solution of $200-\mathrm{mg} \mathrm{NaBH}_{4}$ in $40 \mathrm{~mL}$ of deionized water. The change of solution color from yellow to black indicates the formation of bimetallic compound. An appropriate amount of carbon (Vulcan XC $72 \mathrm{R}$ ) was added. The mixture was kept under stirring for $2 \mathrm{~h}$ at $130{ }^{\circ} \mathrm{C}$, and cooled to room temperature overnight, and the slurry was filtered, washed with water and ethanol, and dried overnight in vacuum oven at $70{ }^{\circ} \mathrm{C}$. These as prepared samples are denoted as $\mathrm{PdNi} / \mathrm{C}-\mathrm{ASP}$. To study the effect of heat treatment on the catalytic activity, the prepared alloy was heat treated at 300, 500, and $700{ }^{\circ} \mathrm{C}$ in the gas mixture of $10 \% \mathrm{H}_{2}-90 \%$ Ar for $3 \mathrm{~h}$, followed by cooling to room temperature. To study the effect of calcination time, the samples were calcined for $1,2,3,4$ and $5 \mathrm{~h}$ at $300{ }^{\circ} \mathrm{C}$.

To investigate the particle size and molecular structure of the BMNA, powder XRD diffractometer (Philips Pan analytical X-ray diffractometer in the Korea Basic Science Institute using $\mathrm{CuK} \alpha$ radiation $\lambda=0.15406 \mathrm{~nm}$ ) measurements were performed. The detailed description of the XRD measurements was reported previously [16]. Inductively coupled plasma atomic emission spectrometer (ICP-AES) used to determine the weight percent of the catalyst components. Using a JEOL 2010F TEM operated at $200 \mathrm{keV}$ morphological and particle distribution studies were carried out for prepared alloys.
Electrochemical studies were performed on a potentiostat (Biologic VSP). Pt mesh counter electrode, a glassy carbon (5 mm dia.) working electrode, and a reference electrode $(\mathrm{Ag} / \mathrm{AgCl}, 3.5 \mathrm{M} \mathrm{KCl})$ were used as a three electrode electrochemical cell. The glassy carbon electrode was polished to a mirror-like finish with $0.05 \mu \mathrm{m}$ alumina (Buehler) before each experiment. A monolayer of the catalyst nanoalloy on the working electrode was prepared by dispersing $1 \mathrm{mg}$ of the nanocatalyst in $2 \mathrm{~mL}$ of deionized water, ultrasonicating until a dark homogeneous dispersion is formed. $20 \mu \mathrm{L}$ of the sample dropped by micropipette onto the glassy carbon electrode. After drying for $15 \mathrm{~min}$ in the oven at $60{ }^{\circ} \mathrm{C}$. Nafion solution $(20 \mu \mathrm{L}$ of $0.025 \mathrm{wt} \%$ ) used to form a thin film on the catalyst monolayer and dried at $60^{\circ} \mathrm{C}$ for $15 \mathrm{~min}$ in oven. The CV was recorded in $\mathrm{N}_{2}$-purged $0.1 \mathrm{M}$ of $\mathrm{HClO}_{4}$ at a scan rate of $50 \mathrm{mV} \mathrm{s}^{-1}$ between -0.2 and $0.8 \mathrm{~V}$ (vs. $\mathrm{Ag} / \mathrm{AgCl}$ ). Before recording the $\mathrm{CV}$, the catalyst surface was electrochemically cleaned by rapid scan rate $\left(200 \mathrm{mV} \mathrm{s}^{-1}\right)$ for 50 cycles between -0.2 and $0.8 \mathrm{~V}$ (vs. $\mathrm{Ag} / \mathrm{AgCl}$ ). After $\mathrm{CV}$ measurements, ORR was subsequently performed in the same potential range in $\mathrm{O}_{2}$-saturated $0.1 \mathrm{M} \mathrm{HClO}_{4}$. The processes were repeated at least three times to ensure repeatability of the data. All the electrochemical measurements were carried out at room temperature.

\section{Results and discussion}

\section{Physical characterization of BMNAs}

ICP-AES analysis was performed to detect the atomic percent of the BMNA components. Ratio of Pd:Ni was found 68:32 and the percent of the prepared bimetallic in the total weight of the electrocatalysts were found around $10 \mathrm{wt} \%$. To determine the alloying effect of $\mathrm{Ni}$ on the $\mathrm{Pd}$ lattice, XRD was applied. Effect of calcination temperature and time on the catalyst shown in Fig. 1a, b. Figure 1a indicates XRD patterns of sample calcined at different temperatures for $3 \mathrm{~h}$ which contains five main characteristic peaks of the fcc crystalline Pd (JCPDS Card 00-0050681) [16], namely the planes (111), (200), (220), (311), and (222), there is no peaks of Ni-containing phase is detected. The broad peaks at $2 \theta=25^{\circ}$ are associated with $\left(\begin{array}{lll}0 & 0 & 2\end{array}\right)$ planes of the hexagonal structure of the carbon Vulcan. From Fig. 1a, for the ASP and ASP treated at 300 and $500{ }^{\circ} \mathrm{C}$, it was observed that there are additional shifted broad peaks appeared at higher angles revealing the presence of smaller particles of bimetallic nanocrystalline.

The formation of bimetallic alloy confirmed by the presence of reflections corresponding to the single fcc phase. Due to alloying, ligament and grain size decreases, the surface strain of Pd lattice increases and the standard 

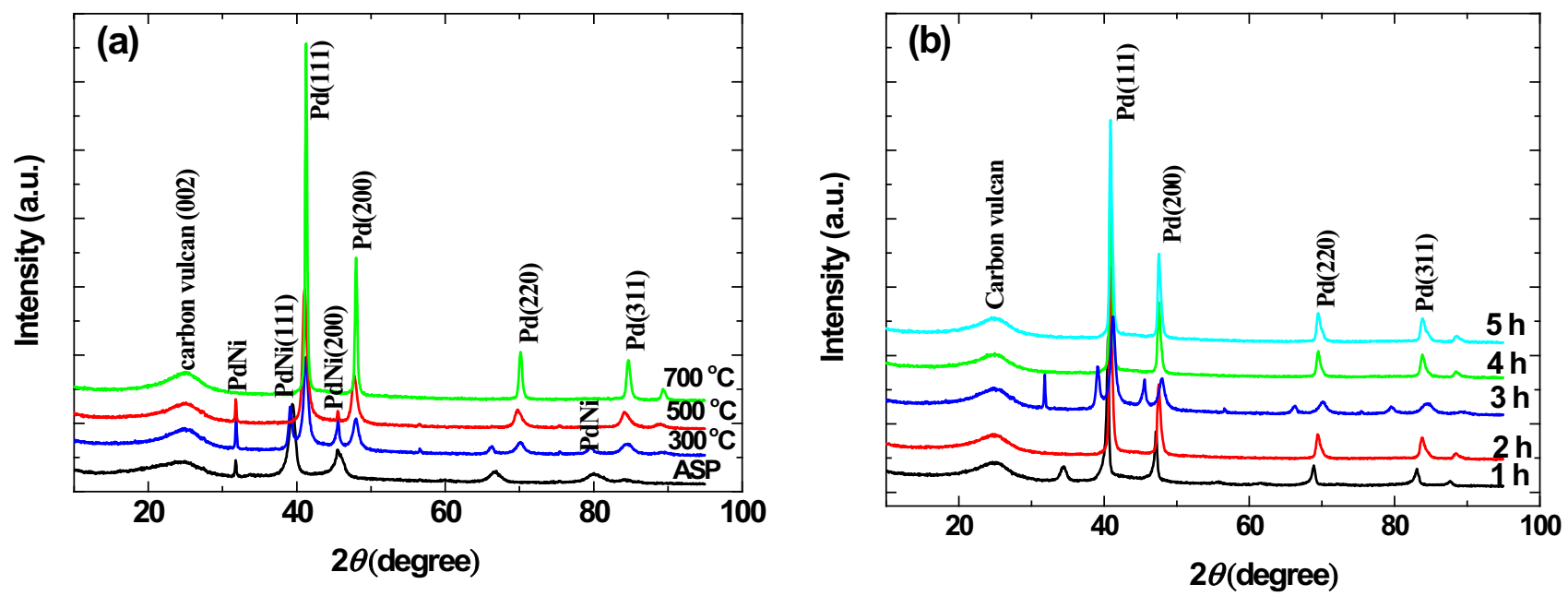

Fig. 1 XRD patterns of the carbon-supported PdNi calcined, a at different temperatures and $\mathbf{b}$ at $300{ }^{\circ} \mathrm{C}$ for different times

sharp peak at $2 \theta \approx 40^{\circ}$ was broad [20]. The single fcc phase which appeared at $2 \theta=33^{\circ}$ correspond to a $\mathrm{PdNi}$ alloy, completely removed at $700{ }^{\circ} \mathrm{C}$ (Fig. 1a) this behaviour related to forming a Pd-rich overlayer on the alloy surface.

The effect of calcination time on the properties of prepared samples at $300{ }^{\circ} \mathrm{C}$ is shown in Fig. 1b. To study the isothermal behaviour of our catalyst at optimal temperature, we prepared five specimens calcined at different times $(1,2,3,4$ and $5 \mathrm{~h})$. During calcination, as a function of time it was observed that, at $3 \mathrm{~h}$ the diffraction broad peaks shifted to higher angles, this attributed to the single phases of the nanocatalyst have a thermally activated nature, this leads to a decrease of the particle size and higher surface activity. Increase of annealing time (4 and $5 \mathrm{~h}$ ) should lead to a better homogenization, and the cell parameter should be closing to its value for the well-annealed alloy which results in an increase of particle size and decrease of surface activity (Table 1). According to the above results, we can conclude that, the optimal temperature should be thus around $300{ }^{\circ} \mathrm{C}$ for $3 \mathrm{~h}$. The properties of the prepared alloy are shown in Table 1.

The active surface area $S$ in $\mathrm{m}^{2} \mathrm{~g}^{-1}$ was calculated using the equation $S($ area $)=\frac{6000}{d \rho}$ for spherical particles [16], where $d$ is the crystallite size (diameter) in $\mathrm{nm}$ obtained from the (111) diffraction line, XRD data (Fig. 1), using the Scherrer equation, $d(\mathrm{~A})=\frac{\kappa \lambda}{\beta \cos \theta}$ [17], and $\rho$ is the density of the PdNi alloy $\left(\sim 11.03 \mathrm{~g} \mathrm{~cm}^{-3}\right)$.

The morphologies of BMNA were observed using TEM (Fig. 2). As a comparison, inhomogeneous distribution of particles, with some regions showing a clear agglomeration, some particles with sizes in the order of few nanometers $(\approx 20 \mathrm{~nm})$ and some others with sizes about $50 \mathrm{~nm}$ can be observed in all samples after calcination at various temperatures (Fig. 2a-c). The spherical shaped with semi aggregation and good crystallinity of NPs with different sizes (from 20 to $50 \mathrm{~nm}$ ) is clearly at lower temperatures (Fig. 2a). The particle size from TEM analysis is higher than that calculated by XRD, due to inside of the polycrystal grain boundaries are not exposed. Figure $2 \mathrm{~d}$ showed a micrograph of sample calcined at $300{ }^{\circ} \mathrm{C}$ for $5 \mathrm{~h}$ which reflects a bad dispersion and higher agglomeration. Ruoshi et al., published that, the addition of Ni to Pd alloy decreases the particle size, which would result in the increase of electroactive surface areas [36]. Shen et al. [37] have reduced PdNi catalysts in different atomic ratios on carbon surface using $\mathrm{NaBH}_{4}$ as a reductant. They had average Pd particle size of $3-3.2 \mathrm{~nm} . \mathrm{Pd}_{1} \mathrm{Ni}_{1} / \mathrm{C}$ catalyst with a Pd loading of $\sim 20 \mathrm{wt} \%$ showed Pd particle size of $3.9 \mathrm{~nm}$ [36]. The reduction of PdNi nanoparticles on

Table 1 Properties of the prepared BMNAs by XRD

\begin{tabular}{|c|c|c|c|c|c|c|c|c|c|}
\hline \multirow{2}{*}{$\begin{array}{l}\text { Heat treatment } \\
\text { Property }\end{array}$} & \multicolumn{4}{|c|}{ Calcination temperature (for $3 \mathrm{~h}$ ) } & \multicolumn{5}{|c|}{ Calcination time at $300^{\circ} \mathrm{C}$} \\
\hline & ASP & $300{ }^{\circ} \mathrm{C}$ & $500{ }^{\circ} \mathrm{C}$ & $700{ }^{\circ} \mathrm{C}$ & $1 \mathrm{~h}$ & $2 \mathrm{~h}$ & $3 \mathrm{~h}$ & $4 \mathrm{~h}$ & $5 \mathrm{~h}$ \\
\hline APS (nm) & 19.35 & 12.83 & 13.96 & 14.94 & 16.87 & 14.76 & 12.83 & 15.35 & 17.32 \\
\hline$S\left(\mathrm{~m}^{2} \mathrm{~g}^{-1}\right)$ & 28.11 & 42.39 & 38.96 & 36.41 & 32.24 & 36.85 & 42.40 & 35.44 & 31.41 \\
\hline
\end{tabular}



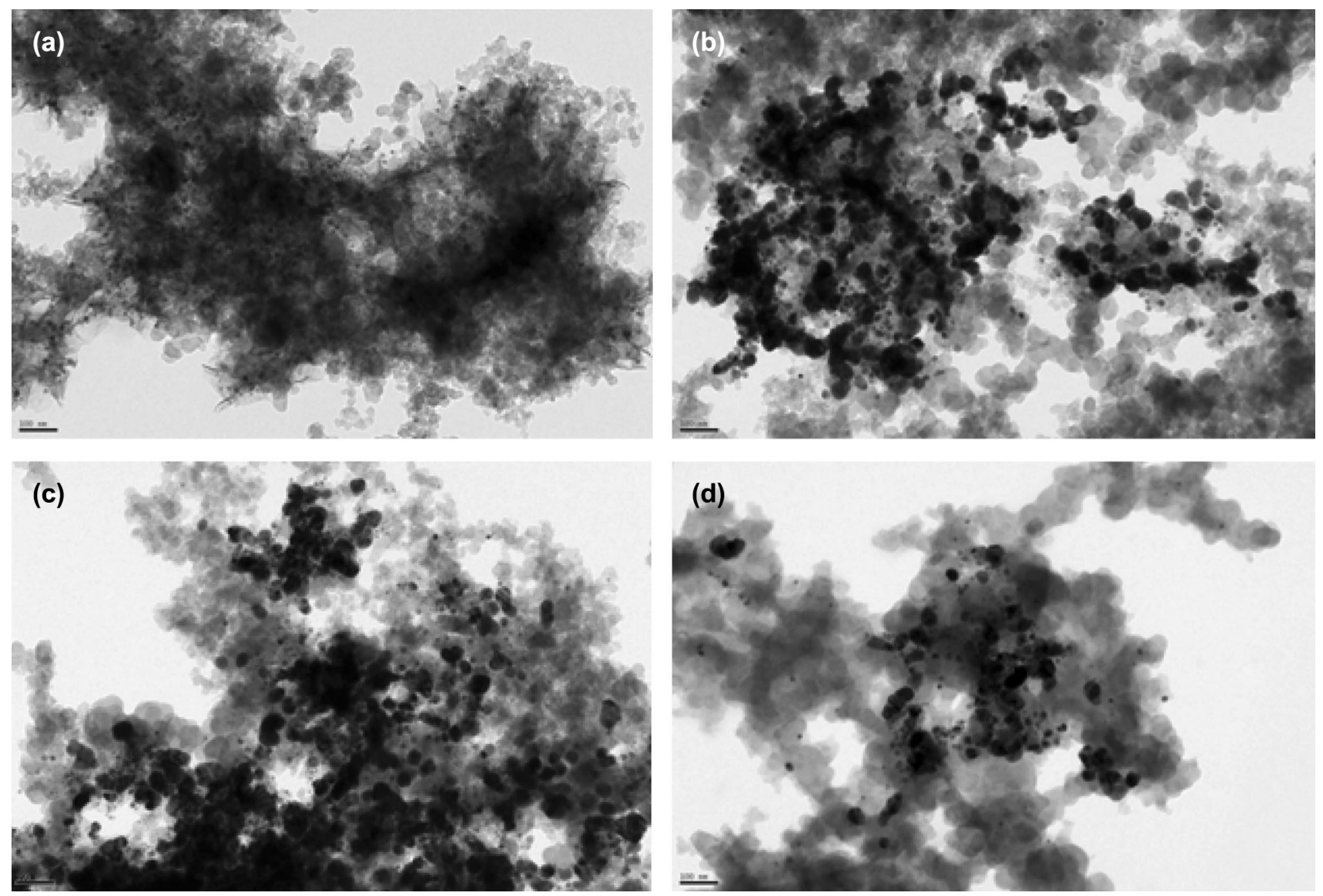

Fig. 2 TEM micrographs of the carbon-supported PdNi alloy calcined for $3 \mathrm{~h}$ a at $300{ }^{\circ} \mathrm{C}$, b at $500{ }^{\circ} \mathrm{C}, \mathbf{c}$ at $700{ }^{\circ} \mathrm{C}$ and $\mathbf{d}$ at $300{ }^{\circ} \mathrm{C}$ for $5 \mathrm{~h}$, respectively, all of these images with $100 \mathrm{~nm}$ magnification

Vulcan XC-72 carbon black support by formic acid and thiourea resulted in larger Pd crystal-sized particles of 4.66 nm [37]. Core/shell Ni@Pd nanoparticles supported on MWCNTs with $20 \mathrm{wt} \%$ total metal content and Pd:Ni atomic ratio of 1:1 had particle size of $6.8 \mathrm{~nm}$ using $\mathrm{NaBH}_{4}$ as a reducing agent [38].

\section{Electrocatalytic activity of BMNAs}

To evaluate the hydrogen adsorption/desorption potentials of the BMNAs, the $\mathrm{CVs}$ were recorded in a $\mathrm{N}_{2}$-purged $0.1 \mathrm{M} \mathrm{HClO}_{4}$ solution at $27{ }^{\circ} \mathrm{C}$ for electrocatalyst as a function of temperature and time (Fig. 3a, b). The smaller values of the potential range from -0.193 to $-0.133 \mathrm{~V}$ was observed for the catalyst calcined at lower temperature for $3 \mathrm{~h}$. The existence of smaller particles of electrocatalyst at lower temperature for $3 \mathrm{~h}$ results in an increase of the electrocatalytic activity and minimizes the potential range of hydrogen adsorption/desorption processes. The starting potential for the bimetallic oxide formation in the positive direction and the reduction in the negative direction is slightly shifted to more positive potential for the catalysts calcined at lower temperature compared to those at higher temperature. This indicates that the chemisorption of oxygenated species on the Pd sites formed at (above $0.5 \mathrm{~V}$ vs. $\mathrm{Ag} / \mathrm{AgCl}$ ) inhibited at lower potential, and thus the electrocatalytic enhancement.

\section{Catalytic activity of BMNAs}

Figure 4 shows the single-scan voltammograms for the electrocatalyst coated on glassy carbon rotating disk electrode at different calcination temperatures and times, in an oxygen-saturated $0.1 \mathrm{M}$ of $\mathrm{HClO}_{4}$ solution, and at ambient conditions. The highest ORR activity was observed for the alloy calcined at $300{ }^{\circ} \mathrm{C}$ (Fig. 4a).

This behaviour ascribed to the smaller particle size and higher surface activity was obtained at lower temperatures (Table 1). During the calcination at lower temperature, the palladium atoms tend to migrate to the surface of the alloy nanoparticles because palladium and nickel exhibit a strong trend toward segregation due to the large segregation energy difference between them [18]. The catalyst consists of two metals, one with a low occupancy of d-orbitals (such 

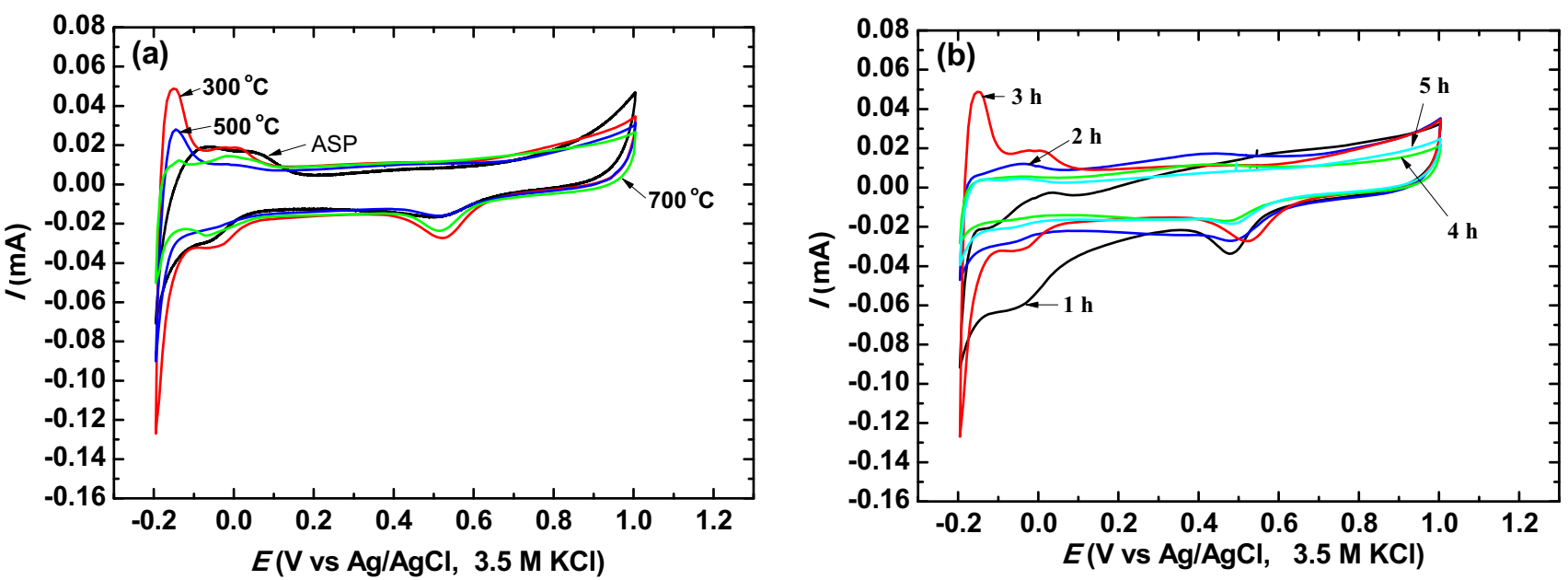

Fig. $3 \mathrm{CV}$ of PdNi/C catalysts calcined a at different temperatures and $\mathbf{b}$ at $300{ }^{\circ} \mathrm{C}$ for different times
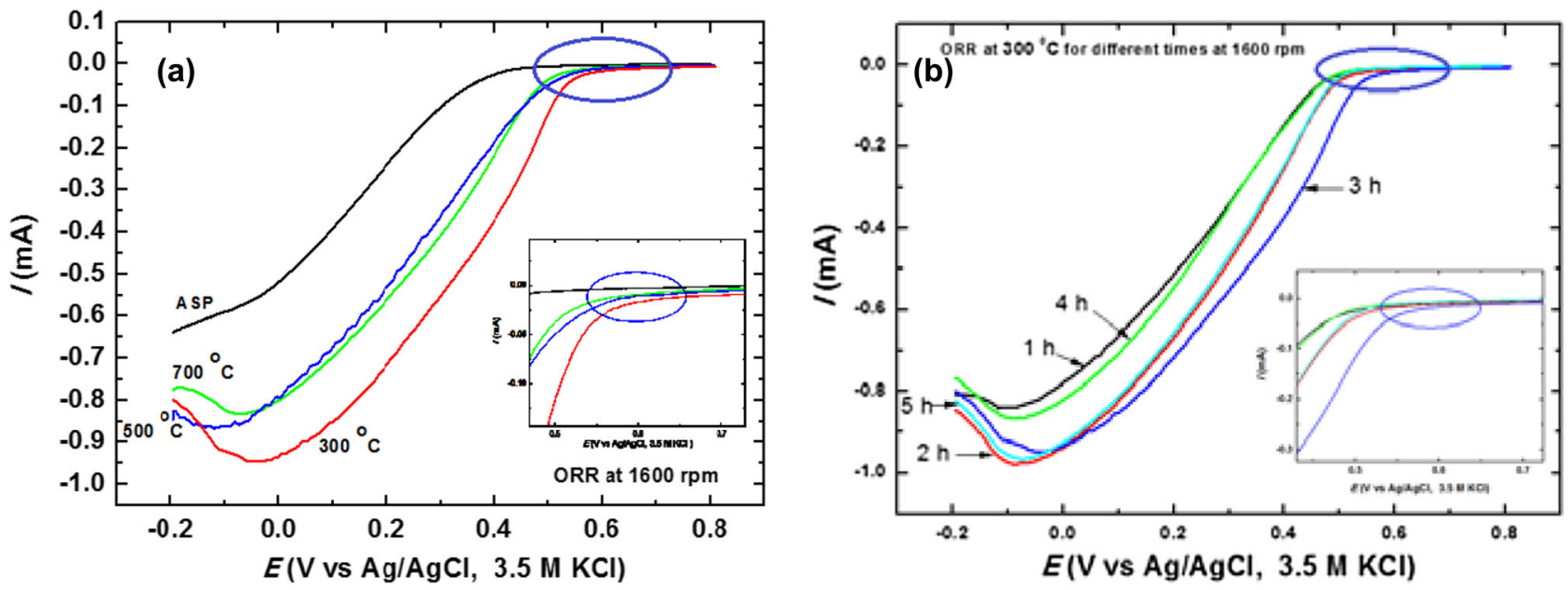

Fig. 4 Single scan voltammograms for $\mathrm{PdNi} / \mathrm{C}$ catalyst calcined $\mathbf{a}$ at different temperatures and $\mathbf{b}$ at $300{ }^{\circ} \mathrm{C}$ for different times

as $\mathrm{Ni}$ ) and the other with fully occupied d-orbitals (such as $\mathrm{Pd}$ ), the d-orbital coupling effect between them can significantly decrease the Gibbs free energy of the electron transfer, resulting in an improvement in ORR kinetics [19]. The incorporation of $\mathrm{Ni}$ with $\mathrm{Pd}$ could bring favourable change of $\mathrm{Pd}$ electron structure to modify the reaction kinetics for ORR on PdNi alloy, thus resulting in a higher efficiency of the reduction process. Sanchez et al., reported that, the intrinsic electrocatalytic properties for the ORR of these bimetallic catalysts $\mathrm{PdNi}$ could be attributed to the bifunctional effect in which the catalytic properties of each of the elements combine in a synergetic fashion to yield a more active surface than each of the elements alone [2]. As a function of time, the electrocatalyst calcined at optimum temperature for $3 \mathrm{~h}$, showed the highest ORR activity (Fig. 4b). This behaviour is attributed to the catalyst calcined for long times that has a larger particle size (smaller surface area) compared to those at moderate periods at the same temperature. For a long time the electrostatic forces between the two metals in our alloy decreases, the particle size increase and surface area decrease leading to a lower activity of the catalyst. The synthetic methods which gave best surface characteristics and high degree of the alloy at lower temperature and moderated time are favourable for increasing the catalytic activity.

\section{Conclusions}

A modified polyol reduction method used to prepare carbon-supported PdNi nanocatalyst in the presence of EG and $\mathrm{NaBH}_{4}$ as reducing agents. The characterizations provided by ICP-AES, XRD and TEM techniques. The smaller particle size (20-50 $\mathrm{nm}$ ) and highly active surface area was obtained at the optimum calcination conditions $\left(300{ }^{\circ} \mathrm{C}\right.$ for $3 \mathrm{~h})$. At a lower temperature and moderated time the 
results of electrocatalytic activity showed enhancement in the efficiency of the ORR process due to the existence of smaller particles of electrocatalyst which minimizes the potential range of hydrogen adsorption/desorption processes and improving the surface morphology.

Acknowledgements This work was supported by the Korea Research Foundation Grant funded by the Korean Government (MOEHRD) (KRF-2008-331-D00094) and a Grant (M2009010025) from the Fundamental R\&D Program for Core Technology of Materials funded by the Ministry of Knowledge Economy, Republic of Korea.

Open Access This article is distributed under the terms of the Creative Commons Attribution 4.0 International License (http:// creativecommons.org/licenses/by/4.0/), which permits unrestricted use, distribution, and reproduction in any medium, provided you give appropriate credit to the original author(s) and the source, provide a link to the Creative Commons license, and indicate if changes were made.

\section{References}

1. Debe, M.K.: Electrocatalyst approaches and challenges for automotive fuel cells. Nature 486, 43-51 (2012)

2. Sanchez, G.R., Madeira, H.Y., Feria, O.S.: PdNi electrocatalyst for oxygen reduction in acid media. Int. J. Hydrog. Energy 33, 3596-3600 (2008)

3. Kuttiyiel, K.A., Sasaki, K., Su, D., Vukmirovic, M.B., Marinkovic, N.S., Adzic, R.R.: Pt monolayer on Au-stabilized PdNi core-shell nanoparticles for oxygen reduction reaction. Electrochim. Acta 110, 267-272 (2013)

4. Zhang, J.W., Zhang, B., Zhang, X.: Enhanced catalytic activity of ternary NiCoPd nanocatalyst dispersed on carbon nanotubes toward methanol oxidation reaction in alkaline media. J. Solid State Electrochem. 21, 447-453 (2017)

5. Podlovchenko, B.I., Kuznetsov, V.V., Batalov, R.S.: Palladium catalyst modified with molybdenum bronze as a possible alternative to platinum in the methanol oxidation reaction. J. Solid State Electrochem. 20, 589-595 (2016)

6. Tao, B., Zhang, J., Hui, S., Wan, L.: An amperometric ethanol sensor based on a $\mathrm{Pd}-\mathrm{Ni} / \mathrm{SiNW}$ s electrode. Sens. Actuators B 142, 298-303 (2009)

7. Jiang, T., Huai, Q., Geng, T., Ying, W., Xiao, T., Cao, F.: Catalytic performance of $\mathrm{PdNi}$ bimetallic catalyst for glycerol hydrogenolysis. Biomass Bioenergy 78, 71-79 (2015)

8. Obradovic, M.D., Stancic, Z.M., Lacnjevac, U.C., Radmilovic, V.V., Wohlmuthere, A.G., Radmilovic, V.R., Gojkovic, S.L.: Electrochemical oxidation of ethanol on palladium-nickel nanocatalyst in alkaline media. Appl. Catal. B 189, 110-118 (2016)

9. Kovnir, K., Armbrüster, M., Teschner, D., Venkov, T., Szentmiklósi, L., Jentoft, F.C., Gericke, A.K., Grin, Y., Schlögl, R.: In situ surface characterization of the intermetallic compound $\mathrm{PdGa}$ - a highly selective hydrogenation catalyst. Surf. Sci. 603, 1784-1792 (2009)

10. Sharaf, O.Z., Orhan, M.F.: An overview of fuel cell technology: fundamentals and applications. Renew. Sustain. Energy Rev. 32, 810-853 (2014)

11. Meng, H., Zeng, D., Xie, F.: Recent development of Pd-based electrocatalysts for proton exchange membrane fuel cells. Catalysts 5, 1221-1274 (2015)
12. Wang, M., Zhang, W., Wang, J., Wexler, D., Poynton, S.D., Slade, R.C.T., Liu, H.K., Jensen, B.W., Kerr, R., Shi, D., Chen, J.: PdNi hollow nanoparticles for improved electrocatalytic oxygen reduction in alkaline environments. ACS Appl. Mater. Interfaces 5, 12708-12715 (2013)

13. Du, C.Y., Chen, M., Wang, W.G., Yin, G.P., Shi, P.F.: Electrodeposited $\mathrm{PdNi}_{2}$ alloy with novelly enhanced catalytic activity for electrooxidation of formic acid. Electrochem. Commun. 12, 843-846 (2010)

14. Gasteiger, H., Kocha, S., Sompalli, B., Wagner, F.: Activity benchmarks and requirements for Pt, Pt-alloy, and non-Pt oxygen reduction catalysts for PEMFCs. Appl. Catal. B 56, 9-35 (2005)

15. Xu, C.X., Liu, Y.Q., Hao, Q., Duan, H.M.: Nanoporous PdNi alloys as highly active and methanol tolerant electrocatalysts towards oxygen reduction reaction. J. Mater. Chem. A 1, 13542-13548 (2013)

16. Abo Zeid, E.F., Kim, D.S., Lee, H.S., Kim, Y.T.: Temperature dependence of morphology and oxygen reduction reaction activity for carbon-supported Pd-Co electrocatalysts. J. Appl. Electrochem. 40, 1917-1923 (2010)

17. Debaleena, B., Subrata, D.: Trimetallic NiFePd nanoalloy catalysed hydrogen generation from alkaline hydrous hydrazine and sodium borohydride at room temperature. J. Mater. Chem. A 3, 24371-24378 (2015)

18. Dai, L.M., Xue, Y.H., Qu, L.T., Choi, H.J., Baek, J.B.: Metal-free catalysts for oxygen reduction reaction. Chem. Rev. 115, 4823-4892 (2015)

19. Wang, Y.X., Balbuena, P.B.: Design of oxygen reduction bimetallic catalysts: ab initio-derived thermodynamic guidelines. J. Phys. Chem. B 109, 8902-8906 (2005)

20. Xu, C., Liu, Y., Hao, Q., Duan, H.: Nanoporous PdNi alloys as highly active and methanol-tolerant electrocatalysts towards oxygen reduction reaction. J. Mater. Chem. A1, 13542-13548 (2013)

21. Wang, Y., Jiang, K., Cai, W.B.: Enhanced electrocatalysis of ethanol on dealloyed $\mathrm{Pd}-\mathrm{Ni}-\mathrm{P}$ film in alkaline media: an infrared spectroelectrochemical investigation. Electrochim. Acta 162, 100-107 (2015)

22. Calderón, J.C., Ráfales, M.R., Monge, M.J.N., Pardo, J.I., Moliner, R., Lázaro, M.J.: Oxidation of $\mathrm{CO}$ and methanol on PdNi catalysts supported on different chemically-treated carbon nanofibers. Nanomaterials 6, 187-205 (2016)

23. Yi, Q., Chen, Q.: In situ preparation and high electrocatalytic activity of binary $\mathrm{PdNi}$ nanocatalysts with low Pd-loadings. Electrochim. Acta 182, 96-103 (2015)

24. Tang, J., Zhao, X., Zuo, Y., Ju, P., Tang, Y.: Electrodeposited $\mathrm{Pd}-\mathrm{Ni}-\mathrm{Mo}$ film as a cathode material for hydrogen evolution reaction. Electrochim. Acta 174, 1041-1049 (2015)

25. Liu, Z.L., Zhang, X.H., Hong, L.: Physical and electrochemical characterizations of nanostructured $\mathrm{Pd} / \mathrm{C}$ and $\mathrm{PdNi} / \mathrm{C}$ catalysts for methanol oxidation. Electrochem. Commun. 11, 925-928 (2009)

26. Qiu, C., Shang, R., Xie, Y., Bu, Y., Li, C., Ma, H.: Electrocatalytic activity of bimetallic $\mathrm{Pd}-\mathrm{Ni}$ thin films towards the oxidation of methanol and ethanol. Mater. Chem. Phys. 120, 323-330 (2010)

27. Qi, Z., Geng, H., Wang, X., Zhao, C., Ji, H., Zhang, C., Xu, J., Zhang, Z.: Novel nanocrystalline PdNi alloy catalyst for ethanol and ethanol electro-oxidation in alkaline media. J. Power Sources 196, 5823-5828 (2011)

28. Wei, Y.C., Liu, C.W., Kang, W.D., Lai, C.M., Tsai, L.D., Wang, K.W.: Electro-catalytic activity enhancement of Pd-Ni electrocatalysts for the ethanol electro-oxidation in alkaline medium: the promotional effect of $\mathrm{CeO}_{2}$ addition. J. Electrochem. 660, 64-70 (2011)

29. Zhang, Q., Li, Y., Chai, R., Zhao, G., Liu, Y., Lu, Y.: Lowtemperature active, oscillation-free $\mathrm{PdNi}($ alloy)/Ni-foam catalyst 
with enhanced heat transfer for coalbed methane deoxygenation via catalytic combustion. Appl. Catal. B 187, 238-248 (2016)

30. Babu, N.S., Lingaiah, N., Prasad, P.S.S.: Characterization and reactivity of $\mathrm{Al}_{2} \mathrm{O}_{3}$ supported $\mathrm{Pd}-\mathrm{Ni}$ bimetallic catalysts for hydrodechlorination of chlorobenzene. Appl. Catal. B 111-112, 309-316 (2012)

31. Jin, C., Sun, X., Chen, Z., Dong, R.: Electrocatalytic activity of $\mathrm{PdNi} / \mathrm{C}$ catalysts for allyl alcohol oxidation in alkaline solution. Mater. Chem. Phys. 135, 433-437 (2012)

32. Lizana, F.C., Quero, S.G., Amorim, C., Keane, M.A.: Gas phase hydrogenation of $p$-chloronitrobenzene over $\mathrm{Pd}-\mathrm{Ni} / \mathrm{Al}_{2} \mathrm{O}_{3}$. Appl. Catal. A 473, 41-50 (2014)

33. Shao, M.: Palladium-based electrocatalysts for hydrogen oxidation and oxygen reduction reactions. J. Power Sources 196, 2433-2444 (2011)

34. Wang, Y.J., Zhao, N., Fang, B., Li, H., Bi, X.T., Wang, H.: Carbon supported Pt-based alloy electrocatalysts for the oxygen reduction reaction in polymer electrolyte membrane fuel cells: particle size, shape, and composition manipulation and their impact to activity. Chem. Rev. 115, 3433-3467 (2015)

35. Kim, D.S., Kim, T.J., Kim, J.H., Abo Zeid, E.F., Kim, Y.T.: Fine structure effect of PdCo electrocatalyst for oxygen reduction reaction activity: based on X-ray absorption spectroscopy studies with synchrotron beam. J. Electrochem. Sci. Technol. 1, 31-38 (2010)

36. Li, R., Wei, Z., Huang, T., Yu, A.: Ultrasonic-assisted synthesis of $\mathrm{Pd}-\mathrm{Ni}$ alloy catalysts supported on multi-walled carbon nanotubes for formic acid electrooxidation. Electrochim. Acta 56, 6860-6865 (2011)

37. Shen, S.Y., Zhao, T.S., Xu, J.B., Li, Y.S.: Synthesis of PdNi catalysts for the oxidation of ethanol in alkaline direct ethanol fuel cells. J. Power Sources 195, 1001-1006 (2010)

38. Zhao, Y., Yang, X., Tian, J., Wang, F., Zhan, L.: Methanol electrooxidation on Ni@Pd core-shell nanoparticles supported on multi-walled carbon nanotubes in alkaline media. Int. J. Hydrog. Energy 35, 3249-3257 (2010)

\section{Publisher's Note}

Springer Nature remains neutral with regard to jurisdictional claims in published maps and institutional affiliations. 